\title{
Novelty Additional Layer Planning A. H. Nasution Road Norht Sumatera with Range with Hrodi Method
}

\author{
Marwan Lubis \\ Staff Lecture Faculty Engineering University Islam North Sumatera (UISU) \\ Sisingamangaraja Street Teladan, North Sumatera Indonesia
}

Received: July 21, 2017 Accepted: September 22, 2017 Published: September 25, 2017

Doi: 10.5296/ijca.v2i1.11734 URL: https://doi.org/10.5296/ijca.v2i1.11734

\begin{abstract}
Condition of damaged road on A.H.Nasution road to Padang Bulan Which appears: subtle fractures, wavy bits, and descending road surface. All of these are caused by resistance factors from road users that can have an adverse impact on the development of the surrounding area. This paper describes the planning of road surface thickness. Process this plan uses Hot Rolled Overlay Design for Indonesia

(HRODI), where the method and outline of planning activities consist of: Data collection and data analysis. The results show that the thickness of the surface layer (ply adjacent) of the path obtained varying results, ranging from $3 \mathrm{~cm}, 7 \mathrm{~cm}$ to $9 \mathrm{~cm}$ are mixed HRS (Hot Rolled Sheet) and ATBL (Asphalt Treated Base Leveling).
\end{abstract}

Keywords: Damaged road, HRODI Methode, Road A.H.Nasution

\section{Intoduction}

Recognizing the importance of the role of road infrastructure in national development, as well as in regional development in North Sumatra, the stages of planning, implementation, and maintenance of roads should be handled so that path service capability can Fulfilled as per the expectations of road users. The above conditions also apply to the A.H.Nasution road segment located at Km. 8 - Km. 17, whereas in other roads there was a growth in traffic due to the increasing population. In This method resulted in pavement construction damaged, in the form of fine cracks, rough road surface, and the partially curved surface is a constraint factor for road users/traffic. This will have a negative impact on the growth of the surrounding area, as well as no longer economical regarding transportation because it will cause the vehicle speed will go down, faster vehicle damage, wasteful fuel consumption, and increased transportation costs.

With the road conditions as mentioned above, then the required input In decision making to 
handle, improve, and maintain The state of the road. One such effort is the need for a thick design an overlay layer made of commonly used construction As a reference in determining the overlay thickness of the Hot Rolled Sheet (HRS) layer type to be used on the road. Based on these facts, it is necessary to do research Purpose: Designing the overlay of pavement construction on A.H.Nasution road which is made from Hot Rolled Sheet (HRS), using Hot Rolled Overlay Design For Indonesia (RODI).

\section{Literature Review}

The material used in the design of a new pavement with pavement HRODI method is an additional layer construction of road pavement, which is Equipped with design data as follows:

1). Design data required for the design of additional pavement layers These include: a). The condition of a road surface, b). Data on road surface conditions In the form of data from the assessment of surface coating conditions, comfort Vehicle and the weight of the damage. Accumulation of all conditions Road surface expressed in RCI (Road Condition Index)

2). Deflection data that occurs obtained from the examination of deflection conditions On the road surface using the Benkelman Beam (BB) tool.

3). Camber condition data from a cross-sectional road obtained through direct measurement in the field of the width of the road body and The transverse slope of the road body.

4). The traffic condition data on the design yng is the result of the survey Traffic volume, role of road, length and width of pavement, number of lanes, The age of the plan and the data on the growth rate of traffic on the road. All of the above design data are based on a survey result Along the A.H.Nasution road with a length of $+15 \mathrm{Km}$ Types of pavement layers to be designed for additional layer thickness (overlay) With HRODI method is a mixture of hot rolled sheets asphalt type (HRS).

This type of HRS is a mixture of aggregates and asphalt, where aggregate Dominated by filler material (aggregate pass sieve No. 200). Some design parameters used in layered planning Additionally with the HRODI method is a reversed segment, surface condition Road (RCI), longitudinal cross-sectional chamber conditions, and cross-equivalent Cumulative traffic load over the life of the plan. Determination of point deflection (d), where the identification of the deflection value of Means of Benkelman does each point/station (d) measurement of deflection Beam (BB), and the calculation using Equation (1) follows:

$$
d=F m \text {. F1. Fe }(d 4-d 1)
$$

Where:

$\mathrm{d}=$ Deflection back

$\mathrm{Fm}=$ Long tool tool and BB tool tool counter).

$\mathrm{Fe}=$ seasonal and environmental factors

$\mathrm{F} 1=$ Load correction factor

$\mathrm{d} 1$ = Reading $\mathrm{BB}$ dial when the load position is right on the heel of the stem

$\mathrm{d} 4=\mathrm{BB}$ BB loading when the load is $6 \mathrm{~m}$ from the starting point.

Determination of the reversed segment (D) is based on the calculation of the value

Back deflection from any point / station (d). Determination of the value of the reverse 
segment

Determined the following stages:

A. Describes the deflection graph of each point and path length.

B. Describes the graph of the RCI value and path length

C. Spread the graph from road width and path length

D. Divide road segments into segments based on uniformity of conditions

Road in accordance with the assessment of the three graphs mentioned above.

The countdown counts representing each existing segment (D) with

Use equation (2) as follows:

$D=-d+1,64(s)$

Based on the value of additional layer thickness required, then it is done Planning of actual extra layer thickness in the field that is tailored to the type Layer pavement used. In this case, the primary type of overlay is used Is Hot Rolled Sheet (HRS) and if required greater than thickness $3 \mathrm{~cm}$, then added layer Asphalt Treated Base Leveling (ATBL) below it Before the HRS layer.

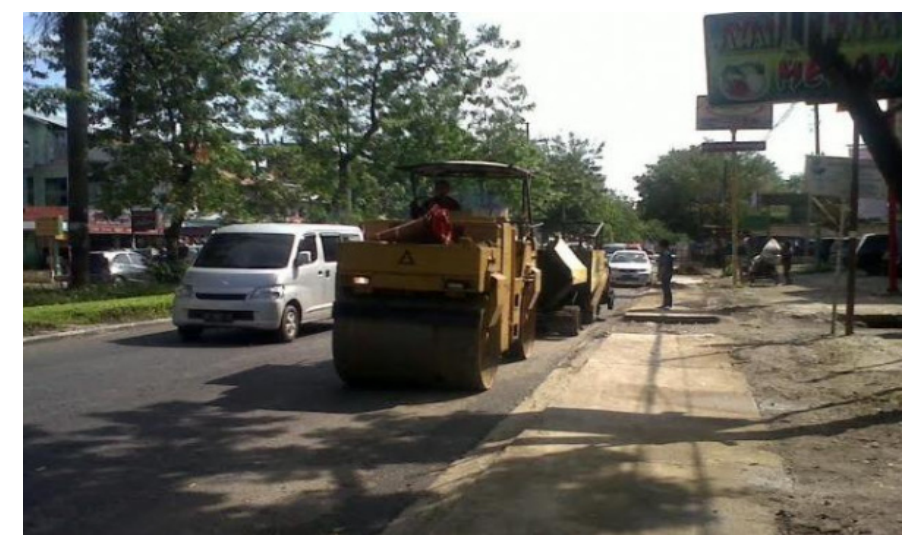

Figure 1. Before layer of road

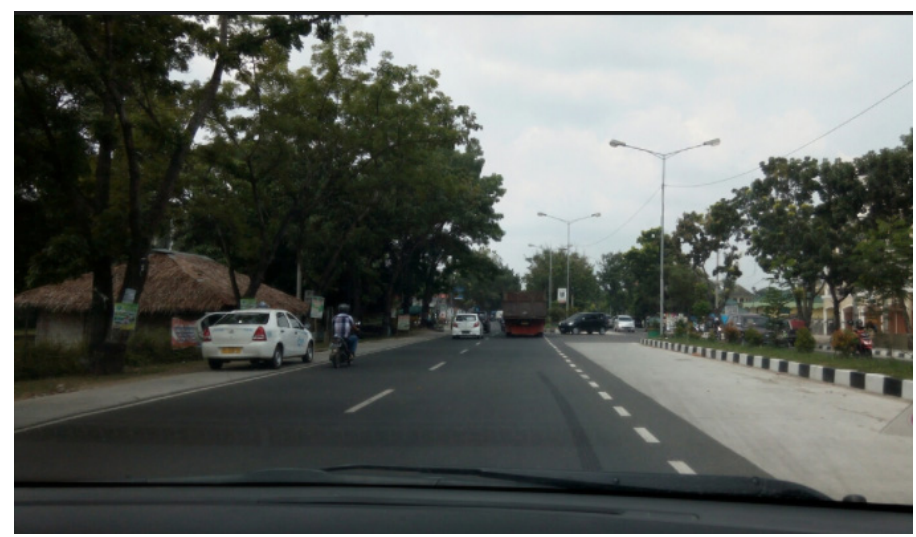

Figure 2. After Layer of Road

\section{Research Methods}

The method used in this research is HRODI method that is

A method of overlay planning correctly used for improvement projects 


\section{Macrothink}

The road in the Directorate General of Highways. This method is used for additional layers made Of the HRS type.

There are 2 (two) types of stages of activities undertaken in layered planning

Additional in this writing are:

1). Collection of design data using secondary survey, i.e., retrieval Data already available to the relevant agencies, in this case, the Project Directors Road Improvement on moon cross roads starting from A.H.Nasution. The obtained data are subsequently reduced/processed for later use in the analysis The design of the new pavement roads in question.

2). Processing and analysis of design data which includes: determination of back deflection point (D), segment deflection (D), calculating the load equivalent amount The traffic axis, and the additional layer thickness.

\section{Results and Discussion}

The results of traffic planning data processing are shown in Table 1, andResults of data processing that expose the values of RCI, Camber, and deflection Segment (D) is presented in Fig.1. The RCI value along the road segment is 4, while the camber value is 2.0 except in the segment Km $57+000-\mathrm{Km} 58+000$ and $\mathrm{Km} 60+000-\mathrm{Km} 62+000$ which is worth 0 (zero). Segment deflection values vary from $0.799 \mathrm{~cm}$ to $2.966 \mathrm{~cm}$.

The thickness of the additional layer of each road segment is shown on Fig. 2. The actual thickness design of the HRS and ATBL layers as indicated In FIG. 3, it is shown that the overlay thickness varies from a thickness of $3 \mathrm{~cm}, 7 \mathrm{~cm}$ Up to $9 \mathrm{~cm}$. The thickness of $3 \mathrm{~cm}$ type of HRS layer dominates along the road. But on certain segments that is at $\mathrm{Km} .57+000$ $-\mathrm{Km} 58+000$, and $\mathrm{Km} 60+000-\mathrm{Km} 62+000$ thick overlay is $7 \mathrm{~cm}$. While the thickness of $9 \mathrm{~cm}$ there On segments $61+000-\mathrm{Km} 62+000$ and $\mathrm{Km} 67+500-\mathrm{Km} 68+100$.

Table 1. Design of Traffic

\begin{tabular}{|c|c|c|}
\hline No & Type of Traffic & Values \\
\hline 1 & Role of Roads & Collector \\
\hline 2 & Leght of Roads & 15 \\
\hline 3 & Traffic growth factor $; 1 \%$ & 7.0 \\
\hline 4 & Pavement width & 5 \\
\hline 5 & Plans ( Years) & 5 \\
\hline 6 & Total of ways & 2 ways \\
\hline 7 & Volume of Traffic & \\
\hline & a. Cars & 1.711 \\
\hline & b. Truck & 333 \\
\hline & c. Heavy Truck & 32 \\
\hline 8 & Other Equivalent Load Equivalent Amount (ESA) 1.054 x 106 & $1054 \times 106$ \\
\hline
\end{tabular}




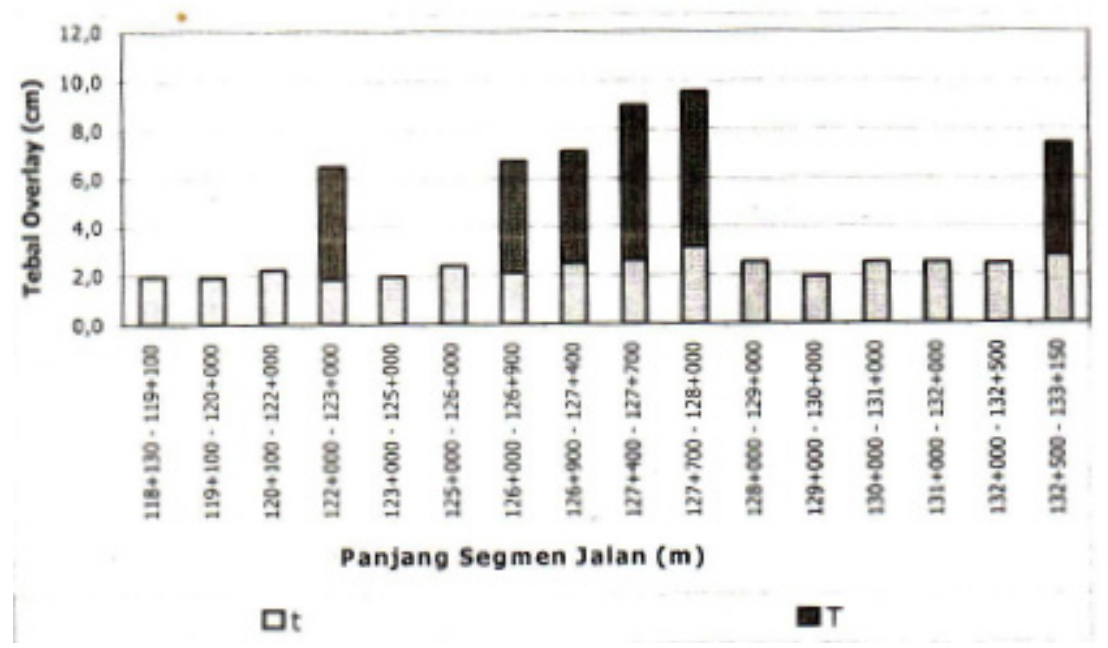

Figure 3. Additional layer design is required

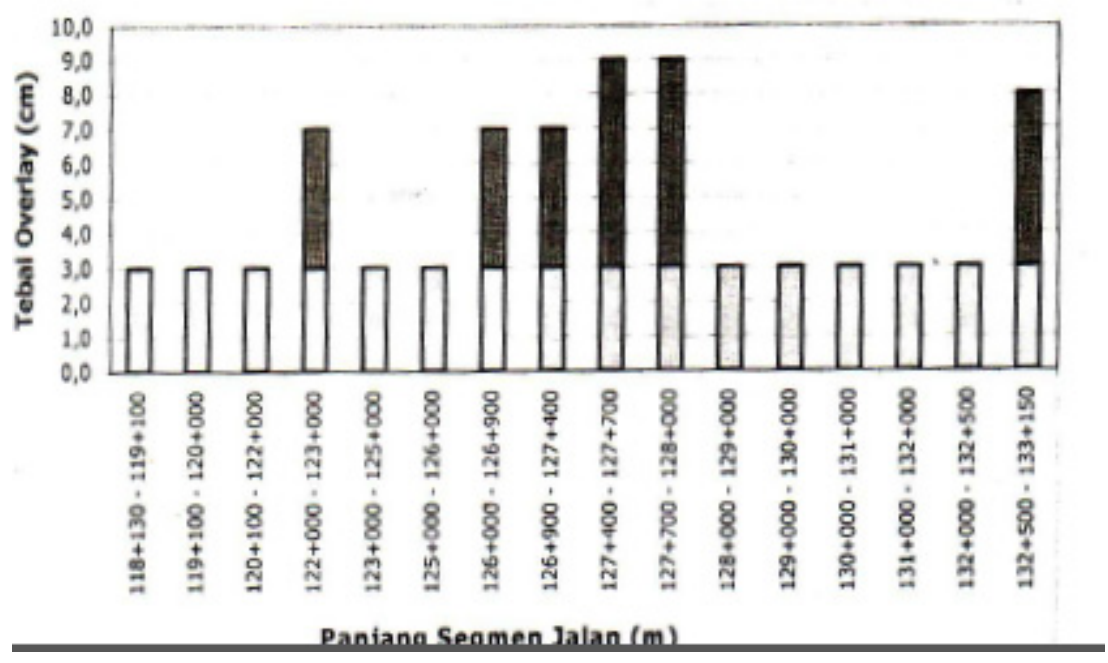

Figure 4. Additional Thick Layer Design Results According to Layer Type

\section{Conclusion}

From the result of planning of additional layer thickness (overlay) with HRODI Method Can be summarized as follows:

1). Thick layers for Jalan A.H.Nasution - Padang Bulan along +15

$\mathrm{Km}$ varies from $3 \mathrm{~cm}, 7 \mathrm{~cm}$ to $9 \mathrm{~cm}$. The extra layer thickness is dominated with a diameter of $3 \mathrm{~cm}$.

2). Additional layer type of pavement with a diameter of $3 \mathrm{~cm}$ is the kind of HRS, while the thickness is greater than $3 \mathrm{~cm}$ to $9 \mathrm{~cm}$ used blend type HRS with ATBL.

\section{References}

Altinel, M., Brown, P., Cline, S., Kartha, R., Louie, E., Mark1, V., ... Singh, A. (2007). Damia: a data mashup fabric for intranet applications. In Proceedings of the 33rd international 
conference on Very large data bases. VLDB Endowment, 1370-1373.

Belleau, F., Nolin, M.-A., Tourigny, N., Rigault, P., \& Morissette, J. (2008). Bio2rdf: Towards a mashup to build bioinformatics knowledge systems. Journal of Biomedical Informatics, 41(5), 706-716. https://doi.org/10.1016/j.jbi.2008.03.004

Expedia, Inc. (2013). Expedia. http://www.expedia.com

Fischer, T., Bakalov, F., \& Nauerz, A. (2009). An overview of current approaches to mashup generation. In K. W. Hinkelmann, \& H. Wache (Eds.), vol. 145. pp. 254-259.

Google Inc. (2013). Google Maps. https://maps.google.com

Liu, X., Hui, Y., Sun, W., \& Liang, H. Towards service composition based on mashup. IEEE Congress on Services, 332-339. https://doi.org/10.1109/SERVICES.2007.67

Wang, G., Yang, S., \& Han, Y. (2009). Mashroom: end-user mashup programming using nested tables. In Proceedings of the 18th international conference on World wide web. $A C M$, 861-870. https://doi.org/10.1145/1526709.1526825

Wong, J., \& Hong, J. (2007). Making mashups with marmite: towards end-user programming for the web. in Proceedings of the SIGCHI conference on Human factors in computing systems. $A C M, 1435-1444$. https://doi.org/10.1145/1240624.1240842

Wong, J., \& Hong, J. (2008). "What do we "mashup" when we make mashups?" in Proceedings of the 4th international workshop on End-user software engineering. $A C M$, $-35-39$.

Wood, J., Dykes, J., Slingsby, A., \& Clarke, K. (2007). Interactive visual exploration of a large spatio-temporal dataset: Reflections on a geovisualization mashup. IEEE Transactions on Visualization and Computer Graphics, 13, 1176-1183. https://doi.org/10.1109/TVCG.2007.70570

Yahoo! Inc. (2013). Yahoo Travel! Trip Planner. http://travel.yahoo.com/trip

Yu, J., Benatallah, B., Casati, F., \& Daniel, F. (2008). Understanding mashup development. Internet Computing, IEEE, 12(5), 44-52. https://doi.org/10.1109/MIC.2008.114

\section{Copyright Disclaimer}

Copyright for this article is retained by the author(s), with first publication rights granted to the journal.

This is an open-access article distributed under the terms and conditions of the Creative Commons Attribution license (http://creativecommons.org/licenses/by/3.0/). 